\title{
Laboratório de Línguas a Distância na UERGS: a constituição de novos domínios de aprendizagem
}

\author{
Mára Lúcia Fernandes Carneiro* \\ Cleci Maraschin ${ }^{* *}$
}

\begin{abstract}
Resumo: O Laboratório de Línguas a Distância da UERGS foi implantado com o apoio de instituições de ensino de línguas, através de convênios de cooperação, O projeto-piloto foi desenvolvido no período de outubro a dezembro de 2002, oferecendo cursos de italiano e inglês para sete Unidades da UERGS e a Reitoria. A idéia de um piloto surgiu da necessidade de tanto os Institutos envolvidos quanto a própria UERGS conhecerem melhor todo o processo que envolve um curso a distância. As aulas foram desenvolvidas através de encontros semanais, via videoconferência, apoiadas pelo uso do ambiente virtual de aprendizagem TelEduc, A observação dos cursos de línguas desenvolvidos permitiu avaliar os acoplamentos tecnológicos estabelecidos em uma experiência de ensino, tradicionalmente centrada no professor e utilizando tanto os recursos para apoio à comunicação oferecidos pelo TelEduc quanto o uso da videoconferência.
\end{abstract}

Palavras-chave: educação a distância, videoconferência, ambientes de aprendizagem

\begin{abstract}
The UERGS language laboratory was implemented with the support of language teaching institutions by means of cooperation agreements. The pilot-project was developed from October through December of 2002, holding Italian and English courses for seven of the UERGS units and for the central administration. The conception of the venture was arisen from the need for the joining language centers and UERGS, as well, to deepen their knowledge of the processes involved in distance education. The classes were held in weekly sessions, by means of video conferences supported by the TelEduc virtual learning environment. The analysis of the language lessons carried out led to an assessment of the technological coupling established in a teaching experience, traditionally centered on the teacher, which made use of both TelEduc and videoconference as supporting resources to communication.
\end{abstract}

Key-words: distance education, videoconference, learning environments

\section{LabLad - Laboratório de Línguas a Distância}

A UERGS implantou 23 unidades ao longo do Estado durante seu primeiro ano de funcionamento, estando previstas mais 6 unidades até março de 2003. Todos estes locais estão conectados através de uma rede de alta velocidade (256 kbps), cuja infraestrutura é proporcionada pela PROCERGS. Nas unidades, as salas de aula comportam, em média, 40 alunos. As mesas estão organizadas na forma de ilhas, proporcionando um espaço de trabalho integrado, com um computador para cada dois alunos. Em cada sala de aula foi instalado um equipamento para videoconferência, que permite a troca de áudio e vídeo entre todas as unidades conectadas.

A conexão pelo sistema de videoconferência pode ocorrer tanto ponto-a-ponto como multiponto. Neste segundo caso, a conexão ocorre através de um gerenciador de

\footnotetext{
"Engenheira Química, D randa. em Informática na Educação PGIE/UFRGS, UERGS, Coordenadora Núcleo de Informática na Educação, mara@uergs.rs.gov.br

"* Psicóloga, Doutora em Educação, Instituto de Psicologia/UFRGS, Coordenadora do Pós-Graduação em Psicologia Social, clecimar@orion.ufrgs.br 
conferência multiponto, também denominado multipoint control unit ou simplesmente MCU, instalado na PROCERGS e gerenciado remotamente.

No prédio da Reitoria, um estúdio foi instalado para oferecer recursos para o professor tanto ministrar aulas a distância quanto gravar suas aulas. Neste estúdio, além do equipamento de videoconferência, estão disponíveis equipamentos como o quadro branco eletrônico ${ }^{\mathrm{i}}$ e câmera de documentos ${ }^{\mathrm{ii}}$.

Como apoio às atividades extra-classe, a universidade disponibiliza um ambiente virtual de aprendizagem (TelEduc ${ }^{\mathrm{iii}}$ ), onde os professores podem publicar seus materiais didáticos, atividades, exercícios, etc. Este ambiente também proporciona recursos para que os alunos publiquem seus trabalhos, que podem ser corrigidos e comentados pelos professores. Desta forma, amplia-se o espaço tradicional da sala de aula.

A UERGS, detectando a necessidade de ampliar os conhecimentos de seus alunos, professores e empregados na área de línguas estrangeiras, propôs a constituição do Laboratório de Línguas a Distância (LabLaD). O LabLaD foi criado com o objetivo de oferecer cursos de línguas para todas as unidades da universidade, utilizando-se dos recursos para suporte à comunicação e interação proporcionados pela infra-estrutura já constituída.

O projeto-piloto foi desenvolvido no período de outubro a dezembro de 2002, envolvendo a realização de cursos de italiano e inglês, com a parceria de duas instituições renomadas de ensino de línguas: Associação Cultural Italiana do RGS e o Yázigi Internexus, através do estabelecimento de convênios de cooperação. Cada turma teve suas aulas ministradas a partir da Reitoria para outras quatro Unidades.

O NIE está vinculado à Pró-Reitoria de Administração e Planejamento da UERGS e foi criado com o objetivo de apoiar a implantação e uso dos recursos tecnológicos pelos professores e alunos da universidade. Na implantação do Laboratório de Línguas a Distância, o NIE realizou, inicialmente, curso preparatório aos professores participantes. Este curso envolveu a formação no uso do ambiente virtual de aprendizagem TelEduc, permitindo que os professores iniciassem a criação de seus próprios cursos. Na segunda etapa do curso preparatório, os professores conheceram a videoconferência e seus recursos. Inicialmente, assistiram a algumas videoconferências e, posteriormente, participaram de reuniões com outras Unidades da UERGS, permitindo a adaptação aos equipamentos auxiliares (controle remoto da câmera, microfone, câmera de documentos, quadro branco, etc.). Os professores também foram orientados na organização de seu material de apoio às aulas e o NIE providenciou, quando necessário, a digitalização e edição de gravações em áudio e/ou vídeo.

Em paralelo a estas atividades, o NIE orientou os responsáveis pelos equipamentos de videoconferência nas Unidades participantes, acompanhando a instalação e testes dos equipamentos. Ao longo dos cursos de línguas, o NIE organizou e acompanhou todas as aulas a distância, administrando o servidor de videoconferência, com o apoio da PROCERGS.

Em contrapartida, os institutos conveniados ofereceram recursos humanos especializados (professores de línguas) e estruturação dos cursos (conteúdo e material didático). Em alguns casos, a universidade pode optar pela aquisição de livros-texto indicados pelos institutos pelas bibliotecas da universidade para serem disponibilizados aos alunos.

Buscando avaliar o processo de ensino e aprendizagem em um ambiente diferenciado como o LabLad, realizou-se este estudo. nele, buscou-se não só analisar os acoplamentos tecnológicos de $3^{\mathrm{a}}$ ordem (Maturana e Varela, 2001) estabelecidos durante o transcorrer dos cursos, mas também os modelos comunicacionais ali 
constituídos. Para apoiar esta análise, buscou-se subsídios da teoria da Biologia do Conhecer, proposta por Humberto Maturana (1970). A seguir apresentamos alguns fundamentos desta teoria, significativos para o contexto deste estudo.

\section{O acoplamento tecnológico e uma outra ecologia cognitiva}

Maturana define espaço como o domínio de todas as interações possíveis de uma coleção de unidades, estabelecido pelas propriedades destas unidades ao especificar suas dimensões. A teoria da Biologia do Conhecer $(1970,1998,2001)$ considera que há uma interação sempre que duas ou mais unidades, através da atuação recíproca de suas propriedades, modificam sua posição relativa no espaço que elas especificam.

Seguindo estas idéias, pode-se dizer que a estrutura do sistema estabelece uma correspondência mútua e dinâmica com o meio, determinando no sistema um domínio de estados e um domínio de perturbações que lhe permite operar recorrentemente em seu meio, sem desintegração, através de um processo denominado de acoplamento estrutural.

Em outras palavras, o acoplamento estrutural é "a correspondência espaçotemporal efetiva entre as mudanças de estado do organismo e as mudanças recorrentes de estado do meio, enquanto o organismo permanece autopoiético" (Maturana, 2001, p.142).

Maturana e Varela (2001) analisam três graus de acoplamento: aquele que ocorre entre as moléculas que constituem uma célula (acoplamento de primeira ordem), aquele que ocorre em um organismo com seu sistema nervoso (acoplamento de segunda ordem) e aqueles que ocorrem entre organismos com sistema nervoso. Este último é denominado acoplamento de terceira ordem, consequiência das interações recorrentes entre organismos que ocorrem de forma que permitam a manutenção da individualidade de ambos no prolongado devir de suas interações.

Michael Reddy, no livro "Metaphor and Thought" (1979, p.165), propôs uma metáfora para o processo comunicacional. Para este autor, a comunicação é amplamente determinada pelas estruturas semânticas da própria linguagem. E ele estabelece uma relação entre o modelo tradicional de comunicação proposto por Shannon e Weaver (1948) e a linguagem, denominando-a de "metáfora do tubo" (conduit metaphor).

Nesta metáfora, as pessoas, escrevendo ou falando, inserem seus pensamentos ou sentimentos (significados) em palavras. Estas palavras empacotam estes significados e são conduzidas, através de um tubo (a linguagem), de uma pessoa para outra. As pessoas, ouvindo ou lendo, retiram os pensamentos e sentimentos de seu interior.

Esta metáfora está presente na concepção educacional ainda vigente, em que todo o ambiente de sala de aula (mesmo virtual) é estruturado para que o professor (o "falante" ou "emissor") envie suas informações através deste "tubo" para o seu aluno ("ouvinte" ou "receptor"). Em muitas propostas de EAD este mesmo modelo se repete: os ambientes virtuais utilizados, em sua maioria, são apenas um espaço para publicação dos textos ou gravações das aulas ministradas pelo professor. Pouquíssimos são os ambientes que proporcionam recursos para o aluno comunicar-se com o professor e seus colegas. Em geral, estes ambientes utilizam-se somente de recursos como formulários, nos quais os alunos encaminham dúvidas ou comentários diretamente aos professores, sem poder compartilhar com os demais participantes deste processo.

Para contrapor à metáfora do tubo, Reddy propõe um caminho alternativo para conceber a comunicação humana. Justifica sua proposta, afirmando que, para analisar as implicações da metáfora do tubo, é necessário apresentar um modelo diferente (1979, 
p.171). Assim, o autor sugere que consideremos o fato de que, ao falar um com o outro, somos como pessoas isoladas em ambientes levemente diferentes e apresenta uma outra metáfora para o modelo comunicacional que ele denomina de "metáfora dos fabricantes de utensílios". Nela, ele descreve um mundo, dividido em setores, isolados dos demais e em que a comunicação só ocorre através da linguagem e com um uso de um equipamento especial de comunicação. Nesta metáfora, ele busca destacar como a comunicação só se estabelece quando os envolvidos realizam esforços para que um novo domínio de interações se constitua, correspondendo aos acoplamentos de $3^{\circ}$ grau caracterizados por Maturana e Varela.

Nesse estudo pensamos que o acoplamento entre alunos, professores e tecnologia produz outros modos de construir o domínio de ações coletivas. Esse domínio de ações compartilhadas (conceitos, teorias, exercícios, etc.) poderia ser pensada conforme a metáfora do fabricante de utensílios, proposta por Reddy. Nela, cada participante precisa realizar um esforço de construção de uma consensualidade pelos outros e compreender o sentido das mensagens dos outros em seu próprio território de experiências já vivenciadas. Nesta metáfora, o ruído (presente no modelo de Shannon e Weaver) é inerente ao ato comunicativo e o "processo" de comunicação é a resultante de um grande e continuado processo interativo.

\section{A experiência efetiva}

A observação dos cursos de línguas (inglês e italiano) a distância, oferecidos através do Laboratório de Línguas a Distância (LabLaD) da UERGS, permitiu avaliar uma experiência de ensino, tradicionalmente centrada no professor e utilizando tanto os recursos para apoio à comunicação oferecidos pelo ambiente TelEduc quanto o uso da videoconferência.

\subsection{As opções tecnológicas envolvidas}

As aulas do Laboratório de Línguas a Distância utilizaram os recursos do ambiente virtual TelEduc e da videoconferência. No ambiente TelEduc foram publicadas "Agendas" semanais, orientando o trabalho dos alunos. No recurso "Atividades", os alunos encontravam as explicações detalhadas sobre os trabalhos sugeridos. O recurso "Material de Apoio" foi utilizado para publicaçã o de textos, áudio e vídeo como suporte às atividades propostas. Como ferramentas para apoio à comunicação, foram escolhidos o Mural e o Correio. Este foi o principal recurso utilizado para a comunicação com os alunos extra-classe.

Nas videoconferências, o gerenciador multiponto (MCU) foi testadas as configurações que permitiram a transmissão com a opção vídeo preferencial (preferred broadcaster) e ativada por voz. No primeiro caso, o vídeo e áudio dos professores eram enviados aos alunos, enquanto o professor via os alunos que solicitavam a palavra e, no segundo, todos assistiam a quem estava falando, enquanto o professor via quem havia falado por último. 


\subsection{As interações no ambiente TelEduc}

Como somente o Correio, em ambos os cursos, foi utilizado como ferramenta de comunicação extra-classe, os mapas de interação (construídos através do recurso Intermap $^{\text {iv }}$ do TelEduc) foram construídos a partir das trocas de mensagens entre os alunos e os professores do curso.

Os mapas das interações atestam um modelo centrado no professor. No curso de Inglês, os nós da rede são constituídos quase essencialmente pelos professores e a pesquisadora. Esta atuou aqui como suporte aos professores e alunos no uso dos recursos tecnológicos, sem envolver-se com a parte didática.

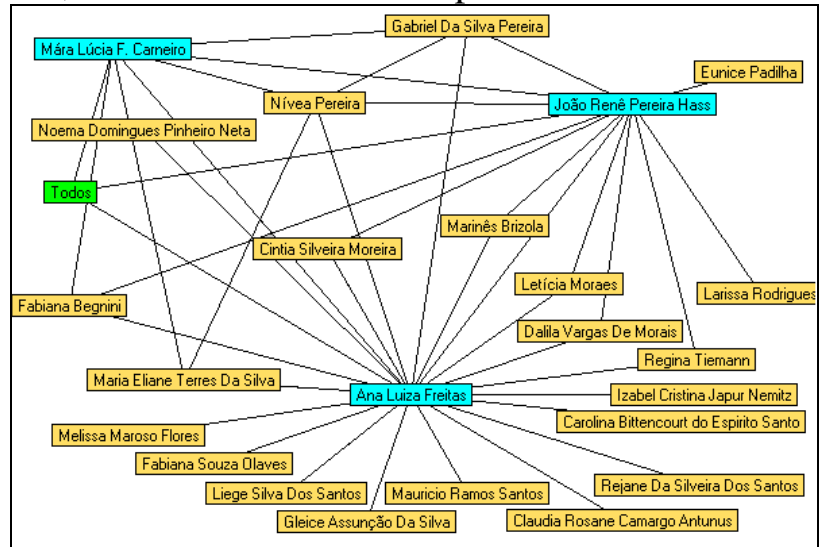

Figura 1 - Interações no curso de Inglês do LabLaD

No entanto, uma análise mais detalhada da Figura 1 mostra que outras redes se constituíram ao longo do curso, com trocas de mensagens ocorrendo entre os alunos. $\mathrm{O}$ sujeito coletivo ("Todos") surgiu somente como resultado das mensagens dos professores.

A análise das interações no curso de Italiano demonstra também a realidade de um curso centrado no professor, sem nenhuma proposta evidente de cooperação entre os alunos.

O mapa da Figura 2 apresenta o mapa das interações ao longo de todo o curso, demonstrando nunca ter surgido outro centro a não ser o do professor do curso. A análise do conteúdo das mensagens trocadas ao longo dos cursos mostra que os assuntos envolviam perguntas dos alunos ao professor sobre o conteúdo e tarefas propostas e as respectivas respostas do professor. Este respondia diretamente ao aluno que havia realizado a pergunta, sem compartilhamento das respostas com o restante do grupo. 


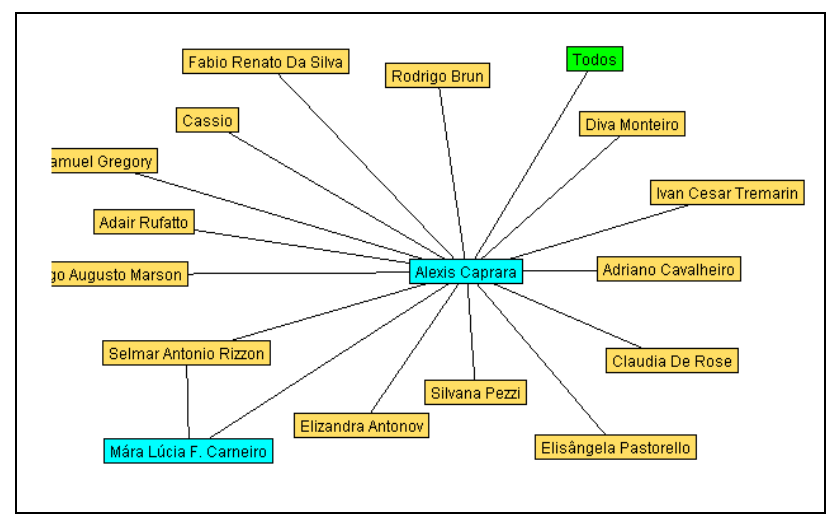

Figura 2 - Interações no curso de italiano no LabLad

\subsection{As interações via videoconferência}

Três aulas de cada curso foram gravadas e depois digitalizadas. A degravação destas aulas permitiu a construção e análise do mapas de interação das aulas de inglês e italiano, construídos de forma semelhante aos gerados pelo InterMap.

\subsubsection{Videoconferências do curso de Inglês}

O mapa das interações da segunda aula de inglês por videoconferência (Figura 3) indica que não ocorreu nenhuma conversa ${ }^{\mathrm{v}}$. Neste início de curso, os professores ainda não estavam familiarizados com os nomes dos alunos e, por este motivo, dirigiam suas mensagens às Unidades ao invés dos nomes dos participantes. Poucos são os alunos que participaram, ficando a maioria como assistente ("receptor").

Além disto, o curso de inglês, na maioria das aulas, era conduzido simultaneamente por dois professores. No início do curso, este fato gerou alguma confusão e nervosismo, pois os dois eram inexperientes no uso dos recursos da videoconferência. Talvez a insegurança daí resultante, tornasse o curso ainda mais centrado nos professores.

A gravação da $15^{a}$ aula (Figura 3), depois de quase dois meses de aula, indica uma aproximação maior da professora com os alunos. No entanto, apesar de já nomear os alunos, as interações ocorreram sempre um-a-um (professor-aluno/aluno-professor), não aparecendo conversas entre os alunos.



Figura 3 - Interações na videoconferência da $15^{\text {a }}$ aula de inglês 
O mapa das interações resultantes da última aula é apresentado na Figura 4. O maior conhecimento da professora tanto dos alunos quanto dos recursos disponíveis (acoplamento tecnológico) permitiu que ela atuasse como promotora das interações entre os alunos. Nestes dois casos, a presença de somente um professor também pareceu facilitar o andamento da aula.

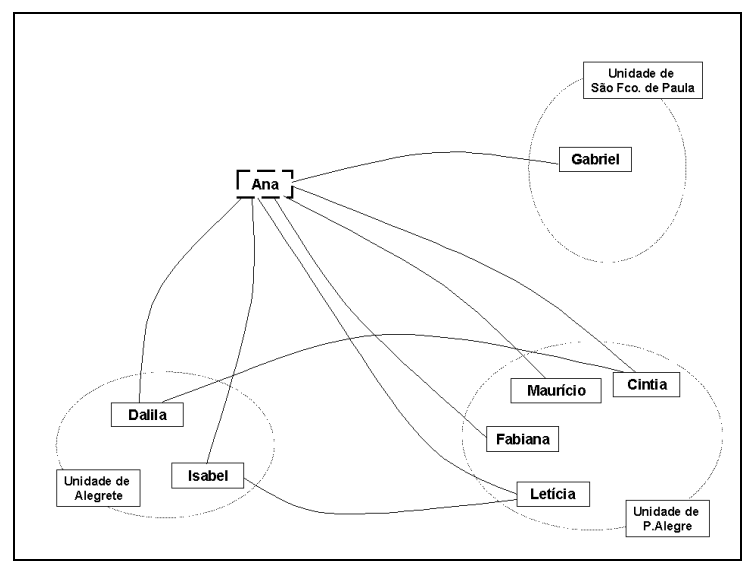

Figura 4 - Interações da videoconferência da última aula de inglês



figura 5 - Interações na videoconferência da $2^{\mathrm{a}}$ aula de italiano

\subsubsection{Videoconferências do curso de italiano}

O mapa da primeira aula gravada do curso de italiano, correspondendo à segunda aula do curso, mostra uma pequena participação dos alunos (Figura 6). O professor, ainda inexperiente no uso dos recursos disponíveis, apresentou uma aula quase que exclusivamente expositiva, com o uso da câmera de documentos.

Outras duas aulas foram gravadas no mês de dezembro. O acoplamento tecnológico é evidenciado pelo manuseio dos recursos pelo professor (dar a palavra aos alunos, uso da câmera de documentos solicitação de troca das Unidades no vídeo pelo gerenciador da videoconferência, etc.) e pela reestruturação das aulas.

O professor passou a chamar os alunos pelo nome para que participassem efetivamente da aula. No entanto, o modelo de aula não se modificou significativamente, já que é o professor quem media e conduz todo o processo, reproduzindo a metáfora do "tubo". Na Figura 6 pode -se observar que o professor dirige-se, em alguns momentos, somente à Unidade, sem nomear os respectivos alunos (interação representada pelas linhas que tocam as elipses). Na última aula, o mapa das 
interações indica que o modelo de comunicação não sofreu alterações, mantendo o professor como figura central e condutora das interações.

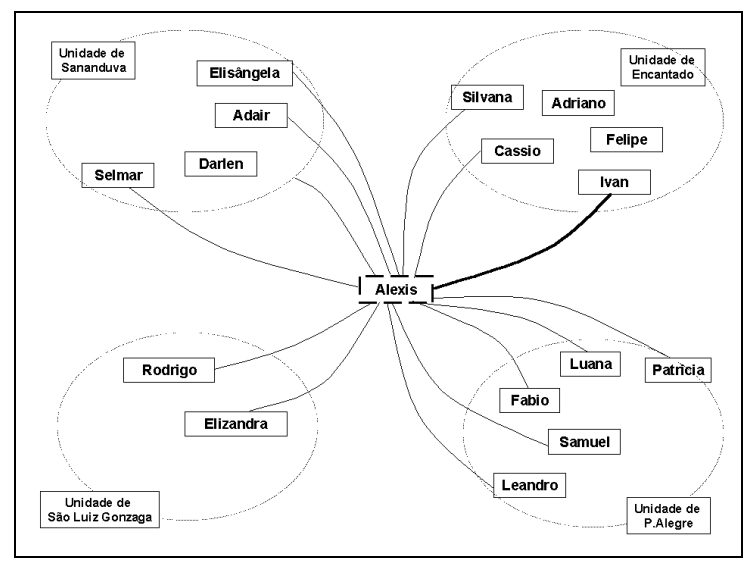

Figura 6 - Interações na videoconferência da $14^{\mathrm{a}}$ aula de italiano

\section{Considerações sobre a experiência}

Nos dois cursos analisados, parece que a visão do processo ensino e aprendizagem dos professores línguas, preocupados com um "treinamento" na língua estrangeira, determinou o modelo de comunicação que emergiu das interações. No entanto, como destaca Freitas (2003), cabe destacar que o processo de aquisição de uma segunda língua seguiu uma metodologia de instrução mediada, diferentemente de uma instrução livre em que não há correção ou não há atenção voltada para a forma da língua.

Tanto os mapas gerados a partir das trocas via Correio do TelEduc quanto os mapas das videoconferências apontam para um modelo comunicacional que segue a metáfora do "tubo". O acoplamento tecnológico ocorreu ao longo da experiência, pois, conforme depoimento dos próprios professores, "apesar da distância entre os locais e a aparente "frieza" do meio através do qual eram ministradas as aulas, estabeleceu-se um forte vínculo entre os participantes do curso o que favoreceu o desenrolar dos encontros com muita motivação e participação de todos (Carneiro, 2002).

No entanto, cabe destacar que esta é uma tendência em estágios iniciais de cursos de línguas e que, provavelmente, se os este estudo tivesse se desenvolvido em grupos em fase de aprendizagem intermediária ou avançada, haveria um desdobramento diferente, pois os alunos realmente iniciam pouco as interações na fase de construção inicial, tanto pelo pouco conhecimento da língua, o que limita, a capacidade interativa, quanto pela hesitação que este fato causa em alunos adultos, já experientes em outras áreas de conhecimento.

A análise das mensagens trocadas através do Correio do TelEduc, no período do curso, mostram uma predominância de mensagens enviadas pelos professores (ou formadores, como o TelEduc os denomina). Nas Figuras 7 e 8 são mostrados os gráficos do $\mathrm{n}^{\circ}$ de mensagens ao longo do tempo. Nelas, as linhas tracejadas representam as mensagens encaminhadas pelos professores, enquanto as linhas contínuas mostram o $\mathrm{n}^{\circ}$ de mensagens enviadas pelos alunos. Nestes gráficos também foram inseridas algumas linhas de tendência, que apontam para uma oscilação no número de mensagens trocadas ao longo do período analisado. 

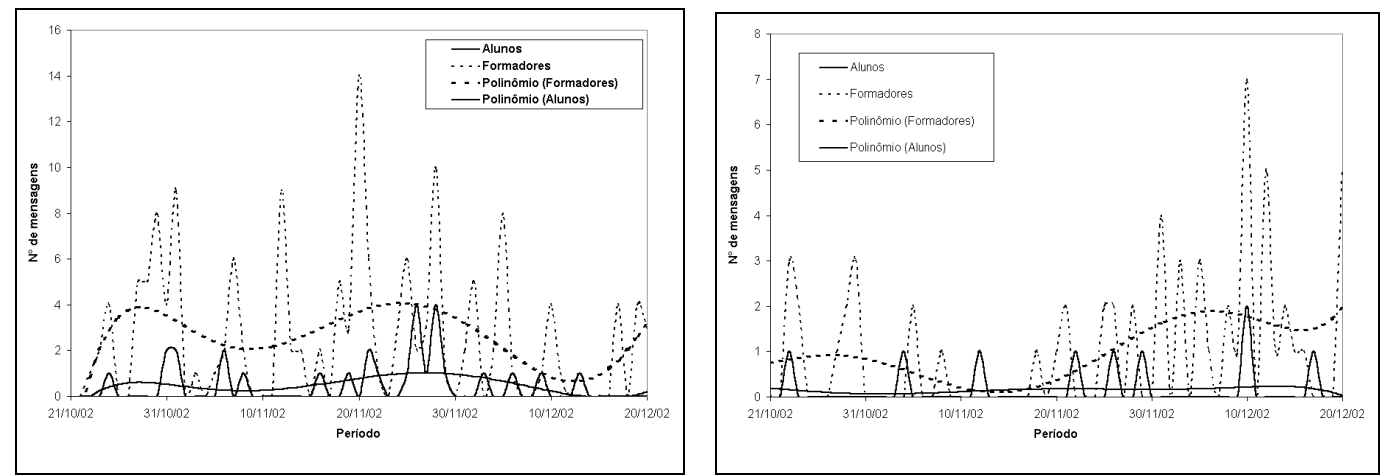

Figura 7 - Mensagens enviadas no curso de inglês Figura 8 - Mensagens enviadas no curso de italiano

O uso da videoconferência, nas duas opções de transmissão testadas também não garantiu o envolvimento nem estimulou a participação dos alunos. Esta ficou restrita às respostas aos professores quando estes as solicitavam, reproduzindo o modelo de uma sala de aula tradicional.

Desta forma, pode-se afirmar que, em experiências de ensino muito centradas no professor, o modelo comunicacional predominante continua sendo o correspondente à metáfora do "tubo". Apesar de considerar as diferenças entre os ambientes dos alunos, os recursos de comunicação disponibilizados não foram suficientes para alterar seu papel de meros receptores para agentes neste processo interativo.

No entanto, como ambos os cursos estudados eram destinados a iniciantes, o treinamento ocorreu tanto em nível das línguas-alvo quanto em nível do aprender a lidar com os recursos e com os instrumentos didáticos propostos. Assim, ocorreram três processos simultâneos: o do uso dos recursos do Teleduc, o da língua alvo e o de entender as tarefas propostas para prática desta língua, o que talvez tenha tornado o processo mais centrado nos professores.

\section{Agradecimentos}

Agradecemos ao Yázigi Internexus e à Associação Cultural Italiana do RGS pelo disponibilização de seus professores, material didático e metodologia de ensino para viabilizar a implantação do Laboratório de Línguas a Distância.

\section{Referências bibliográficas}

CARNEIRO, M.L. LabLad - a experiência de implantação na UERGS. Relatório interno. Publicado em CD-ROM. 2002.

FREITAS, A.L. Laboratório de Línguas a Distância - Inglês. UERGS. Relatório Interno. Porto Alegre, jan. 2002.

MATURANA, H. A ontologia da realidade. Belo Horizonte, Editora da UFMG, 2001. Da biologia à psicologia. Porto Alegre, Artes Médicas, 1998.

Biology of Cognition. Biological Computer Laboratory Research Report BCL 9.0. Urbana IL: University of Illinois, 1970. Disponível na Internet: http://www.enogaia.com/M70-80BoC.html. 
MATURANA, H. e VARELA, F. A árvore do conhecimento: as bases biológicas da compreensão humana. São Paulo, Palas Athena, 2001.

REEDY, M. The Conduit Metaphor - a case of frame conflict in our language about language. In: ORTONY, A. Metaphor and thought. Londres, Cambridge University Press, 1979. p. 164-201.

SHANNON, C.E. A Mathematical Theory of Communication. The Bell System Technical Journal, Vol. 27, pp. 379-423, 623-656, July, October, 1948. Disponível em: <http://cm.bell-labs.com/cm/ms/what/shannonday/shannon1948.pdf>. Acesso em 03 jul 2001. 
${ }^{\mathrm{i}}$ Um "quadro branco" eletrônico em uma sala de aula virtual permite que o aluno remoto veja o que professor escreve ou desenha.

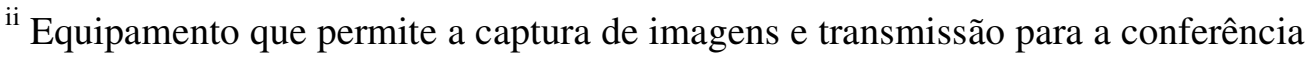

iii $\mathrm{O}$ ambiente virtual de aprendizagem, TelEduc, é resultado de projetos de pesquisa do Núcleo de Informática na Educação (NIED) da UNICAMP, coordenados pela prof ${ }^{\mathrm{a}}$ Heloisa Rocha.

iv O InterMap representa graficamente os dados das ferramentas de comunicação do ambiente TelEduc e foi criada por Luciana Romani do NIED/UNICAMP (ROMANI, 2000).

" Para Maturana (2001, p. 167), a palavra conversar vem da união de duas raízes latinas: cum, que quer dizer "com", e versare que quer dizer "dar voltas com" o outro. Assim, o conversar ocorre durante a interação na coordenação das coordenações consensuais que ali se constituem. 